\title{
Does obesity affect intraocular pressure during laparoscopic surgery?
}

\section{A obesidade afeta a pressão intraocular durante a cirurgia laparoscópica?}

\author{
Basaran Betul', Yilbas Ankay Aysun², Soylu Tulay ${ }^{3}$, Simsek Gurcan ${ }^{4}$ \\ 1. Department of Anesthesiology, Konya Training and Research Hospital, Konya, Turkey. \\ 2. Department of Anesthesiology and Reanimation, Hacettepe University, Faculty of Medicine, Ankara, Turkey. \\ 3. Department of Ophthalmology, Konya Training and Research Hospital, Konya, Turkey. \\ 4. Department of General Surgery, Konya Training and Research Hospital, Konya, Turkey.
}

\begin{abstract}
I Purpose: Obesity is accepted as a risk factor for postoperative visual loss due to possible perioperative elevations in intraocular pressure. This study investigated whether intraocular pressure changes differed according to the body mass index of patients undergoing laparoscopic cholecystectomy. Methods: Thirty obese and 30 non-obese patients (body mass index cutoff point, $30 \mathrm{~kg} / \mathrm{m}^{2}$ ) undergoing laparoscopic cholecystectomy were enrolled. Intraocular pressure was measured at baseline (T1), after induction of anesthesia (T2), 5 min after initiation of mechanical ventilation (T3), 5 min after pneumoperitoneum inflation (T4), 5 min after the patient was placed in the head-up position (T5), 5 min after deflation with the patient in the supine position (T6), and 5 min after extubation with the patient in the 30 degrees upright position (T7). Results: The mean intraocular pressure values of the obese and non-obese groups were similar at T1 (16.60 \pm 2.93 and $16.87 \pm 2.85 \mathrm{mmHg}$ respectively). In both groups, intraocular pressure decreased following initiation of anesthesia (T2) $(\mathrm{p}<0.001, \mathrm{~T} 2 \mathrm{vs} \mathrm{T} 1)$. Intraocular pressure values at T7 were significantly higher than those at T1 in the obese (20.38 $\pm 4.11 \mathrm{mmHg}, \mathrm{p}<0.001)$ and non-obese $(20.93 \pm 4.37 \mathrm{mmHg}$, $\mathrm{p}<0.01)$ groups. There were no significant differences between intraocular pressure values of obese and non-obese patients at any time point. Conclusions: Obesity is not correlated with intraocular pressure during short laparoscopic surgeries with the patient in the head-up position.
\end{abstract}

Keywords: Laparoscopy; Intraocular pressure/etiology; Obesity/ complications; Visual loss

Submitted for publication: March 7, 2018

Accepted for publication: September 15, 2018

Funding: No specific financial support was available for this study.

Disclosure of potential conflicts of interest: None of the authors have any potential conflicts of interest to disclose.

Corresponding author: Betul Basaran.

Department of Anesthesiology, Konya Training and Research Hospital

MeramYeniYol Street, 42090 - Konya, Turkey - E-mail: betulbasaran1@yahoo.com

Approved by the following research ethics committee: Necmettin Erbakan

University, Konya, Turkey (2017-829).
RESUMO | Objetivo: A obesidade é aceita como um fator de risco para a perda visual pós-operatória devido a possíveis elevações perioperatórias da pressão intraocular. Este estudo investigou se as alterações na pressão intraocular diferem de acordo com o índice de massa corporal dos pacientes submetidos à colecistectomia laparoscópica. Métodos: Trinta pacientes obesos e 30 não-obesos (limiar de índice de massa corporal de $30 \mathrm{~kg} / \mathrm{m}^{2}$ ), submetidos à colecistectomia laparoscópica foram incluídos. A pressão intraocular foi medida no início do estudo (T1), após a indução anestésica (T2), 5 min após o início da ventilação mecânica (T3), 5 min após a insuflação do pneumoperitôneo (T4), 5 min após o posicionamento vertical da cabeça (T5), 5 min após a deflação na posição em decúbito dorsal (T6) e 5 min após a extubação com o paciente na posição vertical de 30 graus (T7). Resultados: Os valores médios da pressão intraocular dos grupos obeso e não obeso foram semelhantes no T1 (16,60 \pm 2,93 e 16,87 $\pm 2,85 \mathrm{mmHg}$, respectivamente). Em ambos os grupos, a pressão intraocular diminuiu após o início da anestesia (T2) ( $<<0,001, T 2$ vs T1). Os valores da pressão intraocular em T7 foram significativamente maiores do que aqueles em $\mathrm{T} 1$ nos grupos obesos $(20,38 \pm 4,11 \mathrm{mmHg}, \mathrm{p}<0,001)$ e não obesos $(20,93 \pm 4,37 \mathrm{mmHg}, \mathrm{p}<0,01)$. Não houve diferenças significativas entre os valores de pressão intraocular de pacientes obesos e não obesos em qualquer momento. Conclusões: A obesidade não está correlacionada com a pressão intraocular durante cirurgias laparoscópicas curtas com o paciente em posição de cabeça erguida.

Descritores: Laparoscopia; Pressão intraocular/etiologia; Obesidade/complicações; Perda visual

\section{INTRODUCTION}

Laparoscopic surgeries are encouraged for obese patients because of the shorter hospital stay, less postoperative pain, and fewer wound complications ${ }^{(1,2)}$. However, pneumoperitoneum created for laparoscopic surgery is associated with many physiological changes that may lead to increased intraocular pressure (IOP) ${ }^{(3)}$. 
Furthermore, the increase in intra-abdominal pressure could accentuate the effects of atelectasis that are already increased by general anesthesia, especially in obese patients. The administration of $10 \mathrm{~cm} \mathrm{H}_{2} \mathrm{O}$ PEEP (positive end-expiratory pressure) in mechanically ventilated patients was found to reduce the formation of atelectasis in both obese and normal-weight patients ${ }^{(4,5)}$. On the other hand, PEEP decreases venous return to the heart, which increases orbital venous pressure ${ }^{(6)}$. Obesity decreases the drainage of the episcleral veins due to the increased amount of fatty tissue in the orbital cavity, which rises the IOP by reduction in aqueous humour outflow ${ }^{(7)}$. Concomitant induction of pneumoperitoneum and administration of PEEP may produce significant changes in IOP in obese patients. It is well known that increased IOP can result in ischemic optic neuropathy, the most common type of postoperative vision loss, in the setting of nonophthalmic surgery ${ }^{(8,9)}$.

Previous studies have reported that laparoscopic surgery performed with intraperitoneal carbon dioxide insufflation may result in increased $1 \mathrm{IP}^{(10,11)}$; however, there is a lack of data from obese patients. The aim of this study was to investigate changes in IOP in obese patients undergoing laparoscopic cholecystectomy at different time points and body positions throughout the procedure and to explore the accompanying perioperative factors that influence IOP.

\section{METHODS}

The study was performed at Konya Training and Research Hospital, Konya, Turkey. All study documents and procedures were approved by the institutional review board of Necmettin Erbakan University, Konya, Turkey, and were in accordance with the Declaration of Helsinki. Written informed consent was obtained from all patients. The study included 60 patients aged between 18 and 65 years with American Society of Anesthesiologists (ASA) physical status class 1 or II and who were scheduled to undergo laparoscopic cholecystectomy. Patients were classified as non-obese if their body mass index (BMl) was $<30 \mathrm{~kg} / \mathrm{m}^{2}$ and as obese if their BMl was $\geq 30 \mathrm{~kg} / \mathrm{m}^{2(12)}$. The height and weight of each patient were measured using a standardized height chart and an electronic scale during a preoperative visit. All patients underwent baseline ophthalmic examinations to rule out any ocular pathology. The exclusion criteria included preexisting acute or chronic eye disease; history of eye surgery; current use of systemic $\beta$-blockers, calcium channel blockers, or steroids; pregnancy; pulmonary disease; and patient refusal. Patients with preoperative sitting IOP $>21$ were also excluded.

All patients received the standardized anesthesia protocol, which included standard monitoring (electrocardiography, noninvasive blood pressure, pulse oximetry, and end-tidal $\mathrm{CO}_{2}\left[\mathrm{ETCO}_{2}\right]$ ) and continuous intraoperative infusion of $5 \mathrm{ml} / \mathrm{kg} / \mathrm{h} 0.9 \%$ sodium chloride solution.

Anesthesia was induced with propofol $1.5-2.5 \mathrm{mg} / \mathrm{kg}$ lean body weight (LBW), fentanyl $2-3 \mu \mathrm{g} / \mathrm{kg} \mathrm{LBW}$, and rocuronium 0.6-1 $\mathrm{mg} / \mathrm{kg}$ ideal body weight (IBW). Anesthesia was maintained with $1.5 \%-2.5 \%$ end-tidal sevoflurane concentration in an air/oxygen mixture with a fraction of inspired oxygen $\left(\mathrm{FiO}_{2}\right)$ of 0.4. Mean arterial pressure (MAP) was maintained within $20 \%$ of the preinduction value by titrating remifentanil infusion between 0.025 and $0.2 \mu \mathrm{g} / \mathrm{kg} / \mathrm{min}$. Volume-control mode with a tidal volume of $7 \mathrm{ml} / \mathrm{kg} \mathrm{lBW}$ and $10 \mathrm{cmH}_{2} \mathrm{O}$ PEEP was used for ventilation of the lungs. The $\mathrm{ETCO}_{2}$ level was maintained between 35 and $40 \mathrm{mmHg}$ by adjusting the respiratory rate. The reversal of the neuromuscular blockade was performed by administering neostigmine $50 \mu \mathrm{g} / \mathrm{kg}$ and atropine $10 \mu \mathrm{g} / \mathrm{kg}$ intravenously at the end of the surgery.

IOP measurements were made with Tono-Pen AVIA (Reichert, NY, USA) on the left eye for each position after the instillation of topical anesthesia with proparacaine hydrochloride $0.5 \%$ solution. The probe was located perpendicular to the corneal plane and along the visual axis while measurements were taken. The average was obtained of two repeated IOP measurements that were within $2 \mathrm{mmHg}$ and that had $<5 \%$ error as indicated in the Tono-Pen instruction manual. A repeat measurement was performed if the first two measurements differed by $3 \mathrm{mmHg}$ or more, with outlier measurements excluded. The same ophthalmologist performed all IOP measurements. The ocular perfusion pressure (OPP) was calculated from the measured MAP and IOP. The following equation was used to calculate OPP:

$$
\mathrm{OPP}=2 / 3 \mathrm{MAP}-\mathrm{IOP}
$$

Pneumoperitoneum was created by intraperitoneal insufflation of $\mathrm{CO}_{2}$ while the patient was in the supine position. Later, the patient was placed in the reverse Trendelenburg position (15 degrees from horizontal). Intraperitoneal pressure was maintained at $12 \mathrm{mmHg}$ throughout the surgery. 
IOP, OPP, MAP, and $\mathrm{ETCO}_{2}$ were measured at seven predefined time points. Peak ( $\mathrm{P}$ peak) and mean (P mean) airway pressures were recorded at time points T3 to T6. The time points were the following: T1: Before induction of anesthesia (with the patient awake and resting in the supine position). T2: After induction of anesthesia with the patient in the supine position. T3: 5 min after initiation of mechanical ventilation with the patient in the supine position. T4: 5 min after insufflation of the abdomen with $\mathrm{CO}_{2}$ with the patient in the supine position. T5: 5 min after the head and upper body were elevated at 15 degrees with the abdomen still insufflated with $\mathrm{CO}_{2}$. T6: 5 min after desufflation of the abdomen with the patient in the supine position. T7: 5 min after extubation with the head and upper body elevated by 30 degrees.

\section{Statistical analysis}

SPSS software version 21.0 (SPSS, Chicago, IL, USA) was used for data analysis. The normality of the distribution of continuous variables was determined by the Kolmogorov-Smirnov test. Descriptive statistics for continuous variables were expressed as means \pm SD or medians $\left(25^{\text {th }}-75^{\text {th }}\right.$ percentile), where applicable. Meanwhile, the categorical data were expressed as numbers of cases and percentages.

Mean differences between groups were compared by Student's $t$-test, while the Mann-Whitney U test was applied for comparison of data that were not normally distributed. The categorical data were analyzed using the continuity-corrected chi-square test.

Analysis of variance (ANOVA) with repeated measures was applied to determine whether differences in IOP and hemodynamic parameters at different measurement times were statistically significant. If the p-value from the Wilks' lambda test indicated a statistically significant difference, Bonferroni adjusted multiple comparison was used to determine which differences between measurements at different times were significantly different. Whether the differences in airway pressures among measurement times within groups were statistically significant was evaluated using the Friedman test. If the p-value from the Friedman test indicated a statistically significant difference, the Bonferroni adjusted Wilcoxon signed rank test was used to determine which differences between measurements at different times were significantly different. A p-value $<0.05$ was considered to indicate a statistically significant difference.

\section{Estimation of sample size}

The primary outcome of the study was the difference in IOP between obese and non-obese patients undergoing laparoscopic cholecystectomy. A total sample size of 46 (23 patients in each group) was estimated to detect a difference of at least $3 \mathrm{mmHg}$ in actual change of intraocular pressure $(\Delta \mathrm{IOP})$ at a standard deviation of $3 \mathrm{mmHg}$ in each group, with a power of $95 \%$ and an $\alpha$ error of 0.05 . We chose a difference of at least $3 \mathrm{mmHg}$ because the repeatability of Tono-Pen AVIA has been shown to be about $3 \mathrm{mmHg}$ in approximately $85 \%$ of subjects in the literature ${ }^{(13)}$. Therefore, we decided to include 30 patients in each group to allow for dropout cases. Sample size estimation was performed by using G*Power (Franz Faul, Universität Kiel, Kiel, Germany), version 3.0.10.

\section{RESULTS}

A total of 60 consecutive subjects in the obese and non-obese groups were recruited. The patients' characteristics are shown in table 1 . There were no differences between obese and non-obese patients in mean age, sex ratio, duration of surgery, and baseline IOP levels. The mean BMl was $35.0 \pm 3.5 \mathrm{~kg} / \mathrm{m}^{2}$ in the obese group and $23.5 \pm 2.3 \mathrm{~kg} / \mathrm{m}^{2}$ in the non-obese group. The percentage of patients with ASA physical status Il was $53.3 \%$ in the obese group and $20 \%$ in the non-obese group.

\begin{tabular}{|c|c|c|c|}
\hline Variable & $\begin{array}{c}\text { Non-obese } \\
(n=30)\end{array}$ & Obese $(n=30)$ & $p$-value \\
\hline Age $(y r)$ & $41.6 \pm 13.8$ & $45.8 \pm 11.5$ & $0.202^{*}$ \\
\hline Gender [no. (\%)] & & & $0.398^{\ddagger}$ \\
\hline Female & 19 (63.3) & $23(76.7)$ & \\
\hline Male & $11(36.7)$ & 7 (23.3) & \\
\hline Weight (kg) & $68.0 \pm 11.7$ & $92.3 \pm 8.5$ & - \\
\hline Height (cm) & $169.8 \pm 10.0$ & $162.6 \pm 7.2$ & - \\
\hline BMl $\left(\mathrm{kg} / \mathrm{m}^{2}\right)$ & $23.5 \pm 2.3$ & $35.0 \pm 3.5$ & - \\
\hline ASA [no. (\%)] & & & $0.016^{\ddagger}$ \\
\hline 1 & $24(80.0)$ & $14(46.7)$ & \\
\hline 2 & $6(20.0)$ & $16(53.3)$ & \\
\hline Duration of surgery (min) & $40(38-45.2)$ & $41(36.7-48.2)$ & $0.870^{*}$ \\
\hline
\end{tabular}

Values are means \pm SD or medians $\left(25^{\text {th }}-75^{\text {th }}\right.$ percentile). Boldface values represent statistically significant differences $(p<0.05)$.

$\mathrm{BMI}=$ body mass index; ASA = American Society of Anesthesiologists.

${ }^{*}=$ Student's $t$-test, ${ }^{\ddagger}=$ chi-square test, ${ }^{*}=$ Mann-Whitney U test. 
The changes in IOP in both groups are shown in figure 1 . The induction of anesthesia reduced IOP signi-

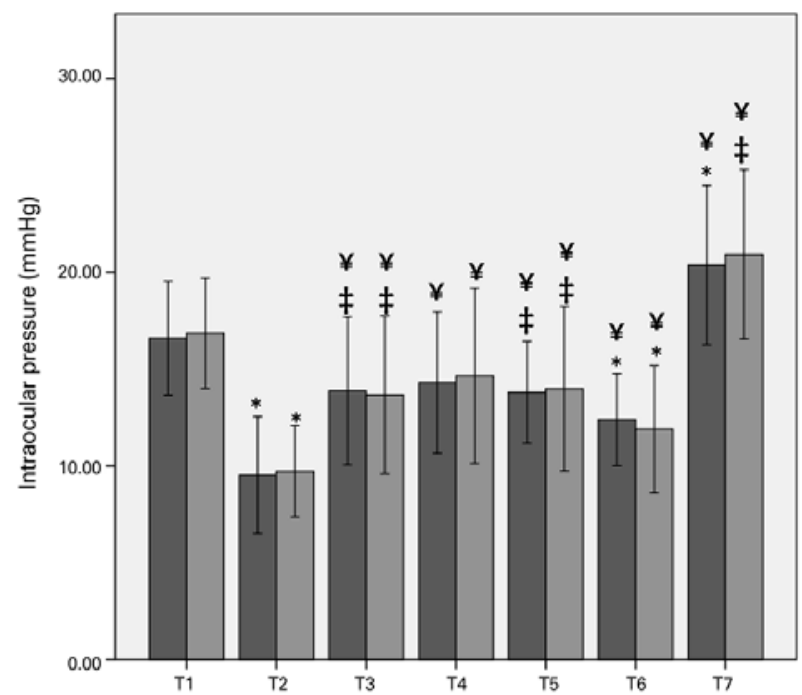

$\mathrm{T} 1=$ Before the induction of anesthesia (with the patient awake and resting in the supine position). $\mathrm{T} 2=$ After the induction of anesthesia with the patient in the supine position. T3= $5 \mathrm{~min}$ after the initiation of mechanical ventilation with the patient in the supine position. T4 $=5 \mathrm{~min}$ after insufflation of the abdomen with $\mathrm{CO}_{2}$ with the patient in the supine position. T5 $=5 \mathrm{~min}$ after the head and upper body were elevated at 15 degrees with the abdomen still insufflated with $\mathrm{CO}_{2}$. T6 $=5$ min after desufflation of the abdomen with the patient in the supine position. $T 7=$ 5 min after extubation with the head and upper body elevated by 30 degrees. Figure 1. Perioperative intraocular pressure (IOP) levels. Data are presented as means, and error bars denote the standard deviation. ${ }^{*} p<0.001$ vs. T1, $¥ p<0.01$ vs. T1, $¥ p<0.001$ vs. T2 for within-group comparisons.

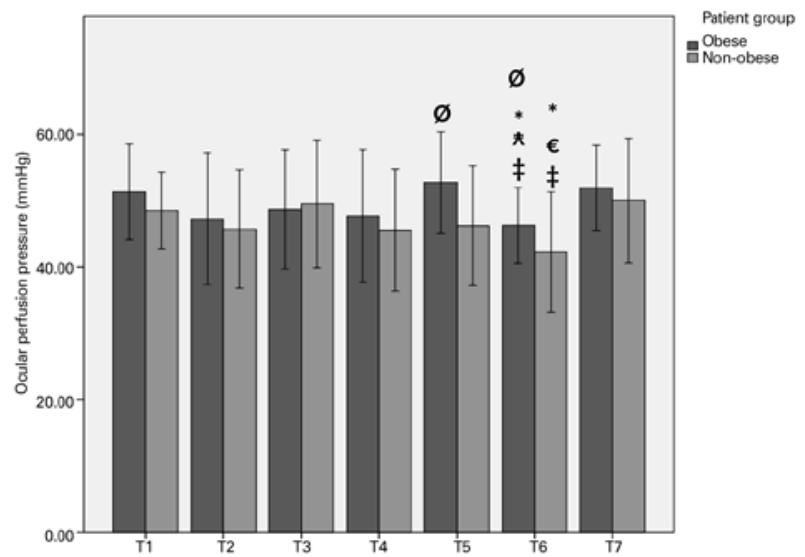

$\mathrm{T} 1=$ Before the induction of anesthesia (with the patient awake and resting in the supine position). T2: After the induction of anesthesia with the patient in the supine position. T3= $5 \mathrm{~min}$ after initiation of mechanical ventilation with the patient in the supine position. T4= $5 \mathrm{~min}$ after insufflation of the abdomen with $\mathrm{CO}_{2}$ with the patient in the supine position. T5 $=5 \mathrm{~min}$ after the head and upper body were elevated at 15 degrees with the abdomen still insufflated with $\mathrm{CO}_{2}$. T6= $5 \mathrm{~min}$ after desufflation of the abdomen with the patient in the supine position. $\mathrm{T} 7=5 \mathrm{~min}$ after extubation with the head and upper body elevated by 30 degrees. Figure 2. Perioperative ocular perfusion pressure levels. Data are presented as means, and error bars denote the standard deviation. ${ }^{*} p<0.05$ versus $T 1, \ddagger p<0.05$ versus $T 5, ¥ p<0.05$ versus $T 7, € p<0.05$ versus T3 for intragroup comparisons. $\varnothing p<0.05$ versus nonobese at each time point. ficantly in both groups $(\mathrm{p}<0.001)$. In both groups, IOP increased significantly after the initiation of mechanical ventilation (T3 vs. T2, $\mathrm{p}<0.001)$. In both groups, IOP 5 min after extubation with the patient in the 30 degrees upright position was significantly higher than at baseline (T7 vs. T1, $p<0.001$ in the obese group and $p<0.01$ in the non-obese group).

Figure 2 shows the average changes in OPP in obese and non-obese patients. OPP significantly differed between the two groups at the head-up and deflation time points.

MAP was maintained within $20 \%$ of the baseline value during surgery in both groups. MAP was higher in obese than in non-obese patients at the head-up and deflation time points (Table 2).

In both groups, $\mathrm{P}$ peak and $\mathrm{P}$ mean levels were higher at 5 min after pneumoperitoneum insufflation and at the head-up position than at 5 min after initiation of mechanical ventilation (T3 vs. T2 and T4 vs. T2, p $<0.001$ and $\mathrm{p}<0.001$, respectively). P peak and $\mathrm{P}$ mean levels were higher in the obese group than in the non-obese group at all time points (Table 3 ).

Table 2. Changes in mean arterial pressure (MAP) and end-tidal $\mathrm{CO}_{2}\left(\mathrm{ETCO}_{2}\right)$

\begin{tabular}{|c|c|c|c|c|}
\hline Variable & $\begin{array}{l}\text { Time } \\
\text { point }\end{array}$ & $\begin{array}{c}\text { Non-obese } \\
\quad(n=30)\end{array}$ & Obese $(n=30)$ & ${ }^{*} p$-value \\
\hline \multicolumn{5}{|c|}{ MAP (mmHg) } \\
\hline & $\mathrm{T} 1$ & $98.03 \pm 8.05$ & $101.83 \pm 12.60$ & 0.170 \\
\hline & $\mathrm{T} 2$ & $83.17 \pm 13.72$ & $85.13 \pm 16.14$ & 0.613 \\
\hline & $\mathrm{T} 3$ & $94.80 \pm 14.07$ & $93.83 \pm 16.09$ & 0.805 \\
\hline & $\mathrm{T} 4$ & $90.30 \pm 16.43$ & $92.97 \pm 16.66$ & 0.535 \\
\hline & T5 & $90.33 \pm 15.70$ & $99.87 \pm 12.26$ & 0.011 \\
\hline & $\mathrm{T} 6$ & $81.23 \pm 13.26$ & $88.03 \pm 8.32$ & 0.021 \\
\hline & $\mathrm{T} 7$ & $106.40 \pm 13.71$ & $108.43 \pm 9.21$ & 0.503 \\
\hline \multicolumn{5}{|c|}{$\mathrm{ETCO}_{2}(\mathrm{mmHg})$} \\
\hline & $\mathrm{T} 1^{\#}$ & $35.90 \pm 0.76$ & $35.87 \pm 0.86$ & 0.874 \\
\hline & $\mathrm{T} 2$ & $35.47 \pm 0.97$ & $35.93 \pm 1.17$ & 0.099 \\
\hline & $\mathrm{T} 3$ & $35.80 \pm 1.58$ & $35.70 \pm 1.24$ & 0.786 \\
\hline & $\mathrm{T} 4$ & $35.77 \pm 1.43$ & $35.13 \pm 0.35$ & 0.025 \\
\hline & T5 & $36.20 \pm 1.73$ & $35.57 \pm 1.04$ & 0.092 \\
\hline & $\mathrm{T} 6$ & $37.50 \pm 1.94$ & $36.97 \pm 1.75$ & 0.269 \\
\hline & $\mathrm{T} 7$ & $37.17 \pm 1.58$ & $36.80 \pm 1.10$ & 0.301 \\
\hline
\end{tabular}

Values are means \pm SD or medians $\left(25^{\text {th }}-75^{\text {th }}\right.$ percentile). Boldface values represent statistically significant differences $(p<0.05)$.

$\mathrm{T} 1=$ Before induction of anesthesia (with the patient awake and resting in the supine position). $\mathrm{T} 2=$ After induction of anesthesia with the patient in the supine position. $\mathrm{T} 3=5 \mathrm{~min}$ after initiation of mechanical ventilation with the patient in the supine position. T4= 5 min after insufflation of the abdomen with $\mathrm{CO}_{2}$ with the patient in the supine position. $\mathrm{T} 5=5 \mathrm{~min}$ after the head and upper body were elevated at 15 degrees with the abdomen still insufflated with $\mathrm{CO}_{2}$. T6 $=5$ min after desufflation of the abdomen with the patient in the supine position. $\mathrm{T} 7=5 \mathrm{~min}$ after extubation with the head and upper body elevated by 30 degrees.

$*=$ student's $t$-test; ${ }^{*}=\mathrm{T}_{1} \mathrm{ETCO}_{2}$ values were measured with nasal cannula. 


\section{DISCUSSION}

In the present study, we investigated whether IOP continued to be normal irrespective of the effect of obesity during laparoscopic cholecystectomy while the patient was in the head-up position. Although $\mathrm{P}$ peak and $P$ mean values were higher in obese patients than in non-obese patients, there were no significant differences in IOP measurements between obese and non-obese patients. In both obese and non-obese patients, IOP was increased after extubation compared with basal levels.

Previous studies reported a positive correlation between BMI and IOP. In contrast, there was no difference between baseline IOP levels in the obese and nonobese groups in our study. The discrepancy between previous studies and the present study seems to be due to differences in the characteristics of the study populations. Whereas Lam et al. ${ }^{(14)}$ and Dogan et al. ${ }^{(15)}$ conducted their studies in obese patients with BMl $>40 \mathrm{~kg} / \mathrm{m}^{2}$, the mean $\mathrm{BMl}$ of the obese group in the present study was $35.0 \pm$ $3.5 \mathrm{~kg} / \mathrm{m}^{2}$. In addition, the mean age of our patients $(41.6$ and 45.8 years in the non-obese and obese groups, respectively) was less than those reported in the Gutenberg Health Study ${ }^{(16)}$ (mean age, 54.7 years) and the Beaver Dam Eye Study ${ }^{(17)}$ (age range, $40-86$ years).

Table 3. Airway pressure measurements according to patient group and follow-up time

\begin{tabular}{lcccc}
\hline Variable & $\begin{array}{c}\text { Time } \\
\text { point }\end{array}$ & $\begin{array}{c}\text { Non-obese } \\
(\boldsymbol{n}=\mathbf{3 0})\end{array}$ & Obese $(\boldsymbol{n}=\mathbf{3 0})$ & ${ }^{{ }^{\sharp}} \boldsymbol{p}$-value \\
\hline P peak & & & & \\
& T3 & $20(19-21)^{\mathrm{a}, \mathrm{b}}$ & $23(21-25)^{\mathrm{a}, \mathrm{b}}$ & $<\mathbf{0 . 0 0 1}$ \\
& T4 & $22(21-24.2)^{\mathrm{a}, \mathrm{c}}$ & $26.5(23.7-28.2)^{\mathrm{a}, \mathrm{c}}$ & $<\mathbf{0 . 0 0 1}$ \\
& T5 & $22(20.7-25)^{\mathrm{b}, \mathrm{d}}$ & $26(24-29)^{\mathrm{b}, \mathrm{d}}$ & $<\mathbf{0 . 0 0 1}$ \\
& T6 & $21(19.7-21.2)^{\mathrm{c}, \mathrm{d}}$ & $23(20-25)^{\mathrm{c}, \mathrm{d}}$ & $\mathbf{0 . 0 0 8}$ \\
& & $<\mathbf{0 . 0 0 1}$ & $<\mathbf{0 . 0 0 1}$ &
\end{tabular}

$\mathrm{P}$ mean

$\begin{array}{cccr}\text { T3 } & 12.5(12-13)^{\mathrm{a}, \mathrm{b}} & 14(12-14)^{\mathrm{b}} & \mathbf{0 . 0 3 9} \\ \text { T4 } & 13(13-14)^{\mathrm{a}, \mathrm{c}} & 14(13-15) & \mathbf{0 . 0 0 4} \\ \text { T5 } & 13(12.7-14)^{\mathrm{b}, \mathrm{d}} & 14(14-15)^{\mathrm{b}, \mathrm{d}} & <\mathbf{0 . 0 0 1} \\ \text { T6 } & 13(12-13)^{\mathrm{c}, \mathrm{d}} & 14(13-14.2)^{\mathrm{d}} & \mathbf{0 . 0 1 3} \\ & <\mathbf{0 . 0 0 1} & <\mathbf{0 . 0 0 1} & \end{array}$

$p$-value

dians $\left(25^{\text {th }}-75^{\text {th }}\right.$ percentile). Boldface values represent

Values are means \pm SD or medians $\left(25^{1-}-75^{4}\right.$
statistically significant differences $(p<0.05)$.

$\mathrm{T} 3=5$ min after initiation of mechanical ventilation with the patient in the supine position. T4= $5 \mathrm{~min}$ after insufflation of the abdomen with $\mathrm{CO}_{2}$ with the patient in the supine position. T5 $=5 \mathrm{~min}$ after the head and upper body were elevated at 15 degrees with the abdomen still insufflated with $\mathrm{CO}_{2} \cdot \mathrm{T} 6=5 \mathrm{~min}$ after desufflation of the abdomen with the patient in the supine position. $\mathrm{T} 7=5 \mathrm{~min}$ after extubation with the head and upper body elevated by 30 degrees.

${ }^{\mathrm{a} T 3}$ vs. T4 ( $\left.p<0.05\right),{ }^{\mathrm{b}} \mathrm{T} 3$ vs. T5 ( $\left.p<0.05\right),{ }^{\mathrm{C}}$ 4 4 vs. T6 $(p<0.05)$, ${ }^{\mathrm{d}} \mathrm{T} 5$ vs. T6 $(p<0.05)$

$\mathrm{P}$ peak = peak airway pressure; $\mathrm{P}$ mean $=$ mean airway pressure.

${ }^{*}$ Mann-Whitney U test.
The existing literature indicates that laparoscopic surgery performed with the patient in the reverse Trendelenburg position does not cause a rise in IOP. Hwang et al. ${ }^{18)}$ reported a decrease in IOP among patients undergoing laparoscopic cholecystectomy in head-up position compared with patients undergoing laparoscopic surgeries other than cholecystectomy in the Trendelenburg position.. Moreover, Karabayirli et al. ${ }^{(19)}$ found that the IOP remained within the normal range during laparoscopic cholecystectomy with or without the administration of $10 \mathrm{~cm} \mathrm{H}_{2} \mathrm{O}$ PEEP. However, in all these studies, the study subjects had normal BMl. Obesity is accepted as one of the major risk factors for postoperative visual loss ${ }^{(9)}$. Obese patients frequently present with several medical comor-bidities. Evidence suggests that vascular diseases, such as atherosclerosis, vasospastic disease, and diabetes, are related to the dysfunctional autoregulation of ocular blood flow, likely contributing to glaucomatous optic neuropathy ${ }^{(20)}$. Even transient increases in IOP may lead to worsening of ocular perfusion pressure and progression of glaucoma. On the other hand, based on the results of the present study, we can only assume that laparoscopy performed with the patient in the head-up position in obese patients without glaucoma or other ocular diseases may be accepted as a safe procedure.

In a review by Pinkney et al. ${ }^{(8)}$, the authors compared IOP changes with patient positioning in laparoscopic surgery and reported that the surgical position plays a role in the increase of IOP in a time dependent manner Similarly, the results of Awad and Yoo et al. ${ }^{(10,21)}$ demonstrated that IOP increased in patients undergoing robot-assisted laparoscopic radical prostatectomy. Hwang et al. ${ }^{(18)}$ also found that the IOP of patients undergoing laparoscopic gynecologic surgery significantly increased when desflurane was used. Changes in the vascular flow in patients in dependent body positions, such as increased episcleral venous pressure, which increases resistance to conventional outflow, or choroidal vascular congestion, which increases resistance to uveoscleral outflow, could be the most convenient explanation for this rise in IOP. In our study, the mean IOP in both the obese and non-obese groups was under the reference point of the normal eye $(20 \mathrm{mmHg})$ during pneumoperitoneum with the patient in the reverse Trendelenburg position ${ }^{(22)}$. Use of the reverse Trendelenburg position probably prevents the deceleration of venous blood flow and the resulting high IOP. After the induction of anesthesia, the IOP decreased abruptly and 
continued to be in the normal range in both the obese and the non-obese group.

Inhalational anesthetic gases and induction agents (except for ketamine) reduce IOP during nonophthalmic surgery. The fall in IOP is unrelated to the effect of the gases and induction agents on blood pressure and central venous pressure and is more likely to result from a direct action on central control mechanisms ${ }^{(23)}$. The establishment of anesthesia before pneumoperitoneum resulted in a significant decrease in IOP from preoperative values, regardless of patient group.

The duration of pneumoperitoneum, MAP, $\mathrm{ETCO}_{2}$, PEEP, and peak airway pressure are other proven causes that contribute to increased $1 \mathrm{IP}^{(6,24-26)}$. The administration of pneumoperitoneum and PEEP leads to a rise in intrathoracic pressure and an associated increase in central venous pressure ${ }^{(27)}$. Since episcleral venous pressure is correlated with central venous pressure, drainage of the aqueous humor via the episcleral veins decreases as central venous pressure increases during the creation of pneumoperitoneum and administration of PEEP. We hypothesized that the increased amount of intraorbital fat in obese patients may play a role in the compression of the episcleral veins and augment the effects of pneumoperitoneum and $\operatorname{PEEP}^{(7)}$. Our results, however, showed that obesity was not correlated with IOP during laparoscopic cholecystectomy with the patient in the head-up position. Intravenous hypnotic agents and inhalational anesthetics would mask the stimulatory effects of pneumoperitoneum and PEEP on IOP. Additionally, a short operation time and the use of the head-up position may hinder any increases in IOP and its deleterious effects.

MAP was maintained within $20 \%$ of the preoperative value in the current study. Changes in blood pressure within this range are poorly transmitted to the eye ${ }^{(28)}$. Although blood pressure significantly increased in obese patients with the establishment of the head-up position and deflation, IOP was similar in obese and nonobese patients. Overall, our study results show that blood pressure changes within the aforementioned limits do not result in changes in IOP and thus changes in ocular hypoperfusion.

Another proven correlation is that between $\mathrm{ETCO}_{2}$ and $\mathrm{IOP}^{(29)}$. In our study, $\mathrm{ETCO}_{2}$ was maintained relatively constant by adjusting minute ventilation. We found no significant relationship between $\mathrm{ETCO}_{2}$ and IOP. Mechanical ventilation at high $\mathrm{P}$ peak is also known to result in high IOP via increasing intrapulmonary pressure ${ }^{(25)}$. Although the $\mathrm{P}$ mean and $\mathrm{P}$ peak of obese patients were high, IOP values were not affected by these high airway pressures, because of the head-up position and short operation time that prevent the effects of pneumoperitoneum and PEEP on IOP.

This study has several limitations. First, the duration of surgery was relatively short. Studies on patients undergoing spine surgery in the prone position have found a relationship between longer operation times and high IOP. The longer period of insufflation may have resulted in a significant increase in IOP in obese patients. Second, this study was carried out with the patients in the head-up position. Studies on patients in other surgical positions, especially the Trendelenburg position, are needed to explore the effects of surgical position in obese patients. Third, the results of the current study are only valid for relatively healthy patients. Hence, the findings of this study cannot be directly extrapolated to patients with ocular hypertension. Finally, mean BMI was $35.0 \pm$ $3.5 \mathrm{~kg} / \mathrm{m}^{2}$ in the obese group. Studies including morbidly obes e and super-obese patients with BMl $\geq 40 \mathrm{~kg} / \mathrm{m}^{2}$ may yield different results for IOP changes during laparoscopic surgery.

In conclusion, laparoscopic surgery on obese patients in the head-up position did not cause an increase in IOP. The increase in IOP after extubation was within the normal diurnal range in both nonobese and obese patients. Further studies are required to prove the safety of laparoscopy with the patient in the head-down position, longer durations of surgery, and laparoscopy in patients with preexisting eye disease.

\section{REFERENCES}

1. Vargas GM, Sieloff EP, Parmar AD, Tamirisa NP, Mehta HB, Riall TS. Laparoscopy decreases complications for obese patients undergoing elective rectal surgery. Surg Endosc. 2016;30(5):1826-32.

2. Eltabbakh GH, Piver MS, Hempling RE, Recio FO. Laparoscopic surgery in obese women. Obstet Gynecol. 1999;94(5 Pt 1):704-8.

3. Hvidberg A, Kessing SV, Fernandes A. Effect of changes in PCO2 and body positions on intraocular pressure during general anaesthesia. Acta Ophthalmol (Copenh). 1981;59(4):465-75.

4. Talab HF, Zabani IA, Abdelrahman HS, Bukhari WL, Mamoun I, Ashour MA, et al. Intraoperative ventilatory strategies for prevention of pulmonary atelectasis in obese patients undergoing laparoscopic bariatric surgery. Anesth Analg. 2009 Nov;109(5): 1511-6.

5. Eichenberger A, Proietti S, Wicky S, Frascarolo P, Suter M, Spahn DR, et al. Morbid obesity and postoperative pulmonary atelectasis: an underestimated problem [table of contents.]. Anesth Analg. 2002;95(6):1788-92.

6. Teba L, Viti A, Banks DE, Fons A, Barbera M, Hshieh PB. Intraocular pressure during mechanical ventilation with different levels of positive end-expiratory pressure. Crit Care Med. 1993;21(6):867-70. 
7. Karadag R, Arslanyilmaz Z, Aydin B, Hepsen IF. Effects of body mass index on intraocular pressure and ocular pulse amplitude. Int J Ophthalmol. 2012;5(5):605-8.

8. Pinkney TD, King AJ, Walter C, Wilson TR, Maxwell-Armstrong C, Acheson AG. Raised intraocular pressure (IOP) and perioperative visual loss in laparoscopic colorectal surgery: a catastrophe waiting to happen? A systematic review of evidence from other surgical specialities. Tech Coloproctol. 2012;16(5):331-5.

9. Lee LA. Perioperative visual loss and anesthetic management. Curr Opin Anaesthesiol. 2013;26(3):375-81.

10. Awad H, Santilli S, Ohr M, Roth A, Yan W, Fernandez S, et al. The effects of steep trendelenburg positioning on intraocular pressure during robotic radical prostatectomy. Anesth Analg. 2009; 109(2):473-8.

11. Mowafi HA, Al-Ghamdi A, Rushood A. Intraocular pressure changes during laparoscopy in patients anesthetized with propofol total intravenous anesthesia versus isoflurane inhaled anesthesia [table of contents.]. Anesth Analg. 2003;97(2):471-4.

12. Centers for Disease Control and Prevention [Internet]. Defining adult overweight and obesity. [cited 2016 June 16]; Available from: https://www.cdc.gov/obesity/adult/defining.html

13. Bhartiya S, Bali SJ, James M, Panda A, Dada T. Test retest variability of TonoPen AVIA. Indian J Ophthalmol. 2013;61(3):129-31.

14. Lam CT, Trope GE, Buys YM. Effect of Head Position and Weight Loss on Intraocular pressure in Obese Subjects. J Glaucoma. 2017;26(2):107-12.

15. Dogan B, Kazim Erol M, Dogan U, Habibi M, Bulbuller N, Turgut Coban D, et al. The retinal nerve fiber layer, choroidal thickness, and central macular thickness in morbid obesity: an evaluation using spectral-domain optical coherence tomography. Eur Rev Med Pharmacol Sci. 2016;20(5):886-91.

16. Hoehn R, Mirshahi A, Hoffmann EM, Kottler UB, Wild PS, Laubert-Reh D, et al. Distribution of intraocular pressure and its association with ocular features and cardiovascular risk factors: the Gutenberg Health Study. Ophthalmology. 2013;120(5):961-8.

17. Klein BE, Klein R, Linton KL. Intraocular pressure in an American community. The Beaver Dam Eye Study. Invest Ophthalmol Vis Sci. 1992;33(7):2224-8.
18. Hwang JW, Oh AY, Hwang DW, Jeon YT, Kim YB, Park SH. Does intraocular pressure increase during laparoscopic surgeries? It depends on anesthetic drugs and the surgical position. Surg Laparosc Endosc Percutan Tech. 2013;23(2):229-32.

19. Karabayirli S, Çimen NK, Muslu B, Tenlik A, Gözdemir M, Sert H, et al. Effect of positive end-expiratory pressure administration on intraocular pressure in laparoscopic cholecystectomy: randomised controlled trial. Eur J Anaesthesiol. 2016;33(9):696-9.

20. Moore D, Harris A, Wudunn D, Kheradiya N, Siesky B. Dysfunctional regulation of ocular blood flow: A risk factor for glaucoma? Clin Ophthalmol. 2008;2(4):849-61.

21. Yoo YC, Shin S, Choi EK, Kim CY, Choi YD, Bai SJ. Increase in intraocular pressure is less with propofol than with sevoflurane during laparoscopic surgery in the steep Trendelenburg position. Can J Anaesth. 2014;61(4):322-9.

22. Newell FW, Krill AE. Diurnal Tonography in Normal and Glaucomatous Eyes. Trans Am Ophthalmol Soc. 1964;62:349-74.

23. Murgatroyd $\mathrm{H}$, Bembridge J. Intraocular pressure. Contin Educ Anaesth Crit Care Pain. 2008;8(3):100-3.

24. 24. Molloy BL. Implications for postoperative visual loss: steep trendelenburg position and effects on intraocular pressure. AANA J. 2011;79(2):115-21.

25. Johnson DS, Crittenden DJ. Intraocular pressure and mechanical ventilation. Optom Vis Sci. 1993;70(7):523-7.

26. Klein BE, Klein R, Knudtson MD. Intraocular pressure and systemic blood pressure: longitudinal perspective: the Beaver Dam Eye Study. Br J Ophthalmol. 2005;89(3):284-7.

27. Hirvonen EA, Poikolainen EO, Pääkkönen ME, Nuutinen LS. The adverse hemodynamic effects of anesthesia, head-up tilt, and carbon dioxide pneumoperitoneum during laparoscopic cholecystectomy. Surg Endosc. 2000;14(3):272-7.

28. Riva CE, Sinclair SH, Grunwald JE. Autoregulation of retinal circulation in response to decrease of perfusion pressure. Invest Ophthalmol Vis Sci. 1981;21(1 Pt 1):34-8.

29. Petounis AD, Chondreli S, Vadaluka-Sekioti A. Effect of hypercapnea and hyperventilation on human intraocular pressure general anaesthesia following acetazolamide administration. $\mathrm{Br} J$ Ophthalmol. 1980;64(6):422-5. 